\title{
PENGGUNAAN STRATEGI REPRESENTASI VISUAL DALAM PEMBELAJARAN APRESIASI PROSA FIKSI
}

\author{
oleh Yuni Pratiwi \\ UM Malang
}

\begin{abstract}
The use of a representational strategy in the teaching of prose fiction appreciation could give students more chances to use non-linguistic symbols in expressing the results of their literature appreciation. The use of non-linguistic symbols has the power of driving away the boredom students experience in using the usual appreciation techniques as well as giving them more chances to create and build their personal meaning in social interaction, enhancing their critical thinking, and empowering them in giving strong argumentation in enjoyable learning contexts. The non-linguistic symbols are many in kind. They are, among others, colored pie charts, sketches, measuring scale figures, and comic pictures.
\end{abstract}

Keywords: visual representation, prose fiction appreciation, non-linguistic symbols

\section{A. PENDAhuluan}

Pembelajaran apresiasi sastra di sekolah bertujuan mengembangkan kemampuan siswa dalam menikmati, menghayati, memahami, dan memanfaatkan karya sastra untuk mengembangkan kepribadiaan, memperluas wawasan kehidupan, serta meningkatkan pengetahuan dan kemampuan berbahasa (Kurikulum Mata Pelajaran Bahasa dan Sastra Indonesia, 2003:1). Tujuan tersebut dicapai melalui pembelajaran apresiasi puisi, drama, prosa fiksi, kritik sastra, dan penulisan kreatif sastra.

Pembelajaran prosa fiksi dalam mata pelajaran Bahasa Indonesia mencakup empat aspek kemampuan, yakni pengetahuan tentang sejarah dan teori prosa fiksi, apresiasi prosa fiksi, kritik terhadap karya fiksi, dan penulisan cerpen. Sejarah dan teori prosa fiksi dipelajari dengan maksud sebagai pembentukan kerangka berpikir tentang isi, bentuk dan bahasa yang digunakan pengarang dalam menulis prosa fiksi. Selanjutnya, apresiasi prosa fiksi diarahkan pada pengembangan kemampuan menganalisis elemen-elemen fiksional dan pemahaman nilai-nilai (value) yang yang terkandung dalam teks. Lebih lanjut, kemampuan apresiasi dikembangkan ke arah kemampuan untuk melakukan kritik terhadap karya sastra. Adapun kemampuan menulis kreatif dimaksudkan memberikan pemerolehan pengalaman estetik dalam mengekspresikan pengalaman kehidupan, gagasan pikiran, serta perasaan melalui latihan penulisan cerpen.

Pelaksanaan pembelajaran prosa fiksi di lapangan menghadapi beberapa masalah yang cukup serius. Persoalan tersebut, antara lain tidak tersedianya teks prosa fiksi yang sepadan dengan kebutuhan siswa; topik-topik pembelajaran yang mencakup ranah pembelajaran yang amat luas dan alokasi waktu yang belum sebanding dengan jumlah topik; belum efektifnya jaringan informasi tentang berbagai hasil inovasi dalam pembelajaran apresiasi sastra di kalangan para pelaksana pembelajaran di lapangan, belum tersedianya alat evaluasi yang standar dalam pembelajaran prosa fiksi, serta tidak ada kewajiban untuk membaca karya sastra tertentu hingga selesai sepanjang siswa belajar di SMU. 
Masalah-masalah yang tersebut seakan telah menjadi "penyakit menahun" dalam pembelajaran apresiasi sastra dan belum juga ditemukan solusinya.

Pembelajaran prosa fiksi yang dilaksanakan di lapangan dewasa ini pada umumnya dikembangkan dengan strategi konvensional. Kegiatan pembelajaran dirancang dalam tiga tahapan kegiatan yakni pembelajaran teori, pemberian kesempatan kepada siswa untuk membaca teks, dan latihan apresiasi. Latihan apresiasi diarahkan pada pemahaman struktur dan makna teks; pengembangan sikap kritis terhadap struktur dan makna teks; dan pengembangan kreativitas kognitif dalam menggunakan hasil belajar yang telah diperoleh. Kegiatan pembelajaran apresiasi yang dikembangkan guru di kelas, misalnya diskusi kelompok, diskusi kelas, menjawab pertanyaan guru berdasarkan teks yang telah dibaca, dan mengerjakan latihanlatihan yang terdapat dalam buku teks. Hasil apresiasi tersebut dilaporkan secara verbal dalam bentuk penulisan sinopsis, laporan hasil analisis struktur formal dan makna teks, penulisan esai, penulisan resensi, dan penulisan kritik sastra.

Untuk menghimpun hasil belajar apresiasi siswa, beberapa guru berinisiatif memanfaatkan jurnal respon pembaca untuk menghimpun hasil belajar siswa. Seperti dikutip oleh Within (1996) dari Atwell (1987), Harste, Short \& Burke (1988) dan Rief (1992), jurnal respon pembaca ini dapat memberikan kesempatan yang penting bagi siswa untuk menyampaikan respon terhadap sastra di sekolah dasar kelas-kelas bawah, tengah, dan tinggi Respon yang dinyatakan dengan tulisan dapat membantu siswa mengembangan interpretasi ganda terhadap teks (Rosenblatt, 1978 dalam Whitin, 1996). Hal yang patut dicatat, keterbatasan dari bentuk jurnal ini adalah jika siswa telah dapat menyatakan respon dengan menggunakan bahasa, khususnya bagi siswa yang kelompok kelas lanjut, kemungkinan hal ini dapat menimbulkan kebosanan.
Penelitian dan inovasi dalam pengembangan strategi pembelajaran sastra telah banyak dilakukan. Phyllis E. Within (1996) melaporkan bahwa penggunaan respon visual untuk merepresentasikan hasil apresiasi prosa fiksi dapat menarik perhatian dan meningkatkan motivasi belajar siswa. Penelitian tersebut mendeskripsikan pengalaman belajar siswa kelompok kelas tujuh (atau setingkat dengan kelas I SMP) dalam menetapkan dan berbagi hasil penafsiran makna sastra setelah mengkresiakannya dalam bentuk representasitasi visual. Strategi representasi visual dinyatakan dalam bentuk "sketsa-sketsa" yang melibatkan siswa dalam mengkreasikan simbol-simbol, gambar, dan tanda-tanda non linguistik yang lain untuk menyatakan ide-ide umum setelah membaca. Siswa menggunakan sistem tanda-tanda dari seni, matematika, bahasa untuk mengekspresikan pengetahuan perseorangan dan kelompok.

Penelitian yang dilakukan Whitin difokuskan pada upaya untuk meneliti perubahan sketsa (evolution of sketching) dalam dua kelompok dan mengeksplorasi perangkat ini dapat membantu siswa memperkaya pemahaman atas sastra dan kemampuan pemahaman (literacy) itu sendiri. Data dianalisis oleh kedua pihak, yakni guru sebagai peneliti dan siswa. Penelitian ini memberi manfaat praktis terhadap pembelajaran dan menyediakan kesempatan bagi siswa semua usia untuk menetapkan makna teks dengan pilihan sistem tanda..

Manfaat lain yang sangat mononjol dalam penggunaan strategi representasi visual yakni terciptanya konteks pembelajaran yang menyenangkan. Siswa berada pada suasana belajar yang memberi kesempatan untuk mengungkapkan-gagasannya tanpa dibebani perasaan takut salah, sehingga metode representasi visual siswa menjadi titian untuk mengembangkan kemampuan apresiasi yang lebih mendalam dan luas. Hasil representasi visual dapat dikembangkan melalui aktivitas diskusi untuk menggali informasi yang lebih mendalam dengan mengajukan pertanyaan, 
mengorganisasikan argumentasi untuk mendukung gagasan, menarik inferensi berdasarkan gagasan yang diajukan, dan menemukan solusi berbagai masalah yang dimunculkan. Aktivitas diskusi ini sekaligus memberi kesempatan kepada siswa untuk belajar saling menghargai dalam menyampaikan pikiran, menghormati pilihan sikap yang berbeda dalam memecahkan masalah, bersikap arif dalam mengambil setiap keputusan untuk diri sendiri dan kelompoknya.

Rodrigues dan Badaczewski (1978:92) antara lain menyarankan hendaknya tujuan dirumuskan berdasarkan pemilihan karya sastra yang tepat --karya sastra yang tepat untuk siswa dan dalam waktu yang tepat. Untuk itu, guru perlu mempertimbangkan kebutuhan siswa, interses siswa, kemampuan guru untuk mencapai tujuan yang dirumuskan yang telah drumuskannya. Guru hendaknya juga mempertimbangkan hambatan waktu dan faktor-faktor lain yang memungkinkan karya sastra tersebut untuk dibaca. Guru dapat membuat kompromi agar siswa tetap memperoleh kesempatan belajar sastra dengan menekan variabel penghambat sedemikian rupa.

\section{B. PIKIRAN DASAR PENGGUNAAN STRATE G I REPERESENTASI VISUAL}

Beberapa ahli pembelajaran sastra seperti dikutip oleh Whitin (1996) menjelaskan beberapa pikiran dasar yang digunakan sebagai acuan dalam pengembangan strategi representasi visual seperti berikut ini.

(1) Teks sastra mengandung potensi makna yang dapat diinterpreatasikan (Rosenblatt, 1978, Siegel, 1984). Tiap-tiap siswa membangun makna secara personal setelah membaca.

(2) Harste dan koleganya (1984) telah menunjukkan interpretasi setelah membaca dengan sistem komunikasi ganda membuka potensi baru untuk menetapkan makna.

(3) Siswa dapat mengkreasikan makna setelah melakukan interaksi sosial dan mereka tidak dapat mengkreasikannya sendiri.

\section{BEBERAPA CONTOH PENERAPAN STRATEGI REPRESNTASI VISUAL DALAM PEMBELAJARAN PROSA FIKSI}

\section{Penggunaan "Pie Chart" Sastra dalam Apresiasi Karakter Tokoh}

"Pie Chart" sastra digunakan dengan membuat gambar "adonan kue pie" dalam bentuk lingkaran atau bentuk-bentuk lainnya yang berhubungan dengan kue pie. "Pie chart" digunakan siswa untuk merepresentasikan hasil apresiasinya dengan cara membagi "pie chart" menjadi beberapa bagian dan mewarnainya sesuai dengan kepentingan apresiasi. Misalnya, dalam pembelajaran dengan topik "karakter tokoh" siswa menggambar kesimpulan terhadap apresiasi karakter tokoh dengan cara membagi "pie chart" menjadi beberapa bagian sesuai jumlah tokoh yang dianalis karakternya. Selanjutnya, siswa mewarnai hasil pembagian tersebut dengan warna tertentu. Misalnya, pilihan warna putih untuk menggambarkan karakter tokoh yang jujur, pemaaf, setia, dan rendah hati. Warna merah digunakan untuk menggambarkan watak berani, tegas, teguh pendirian. Warna biru untuk menggambarkan kasih sayang, kecerdasan, dan kelembutan. Pilihan warna ini lazimnya disesuaikan dengan penggunaan warna sebagai simbol-simbol budaya di tempat sekolah itu berada. Representasi visual ini digunakan sebagai medium diskusi untuk belajar mengorganisasikan argumentasi dan mempertajam argumentasi, menghubungkan hasil interpretasi dengan pelajaran lain, dan menghitung secara matematis persoalan yang dihadapi tokoh. Lebih lanjut siswa dapat membuat penjelasan verbal melaui aktivitas diskusi atau karangan yang dilaporkan.

Representasi hasil apresiasi melalui "pie chart" misalnya, ketika siswa menganalisis ciri-ciri fisik, sosiologis, dan psikologis tokoh. Jika ciri karakter yang melekat pada seorang tokoh tokoh lebih dari satu maka teknik pewarnaan digunakan secara berlapis atau ganda. "Pie chart" juga dapat digunakan untuk merepresentasikan perasaan tokoh pada sebuah unit peristiwa. Siswa diberi kebebasan untuk 
memberikan pilihan warna untuk menggabarkan perasaan tokoh tersebut. Pada contoh berikut, menggambarkan hasil analisis siswa terhadap karakter tokoh Pak Pong pada cerpen "Jakarta".
Watak Pak Pong

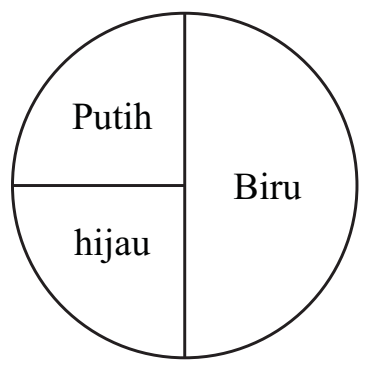

Hasil representasi visual di atas digunakan untuk mengembangan kegiatan pembelajaran selanjutnya. Misalnya, jika "pie cahart" di atas dibuat secara individual oleh siswa, salah seorang siswa dapat ditugasi untuk menyajikannya di depan sambil memberikan penjelasan tentang alasan pemilihan ukuran dan warna dalam analisis karakter yang telah dilakukannya. Selanjutnya, penjelasan tersebut diikuti dengan kegiatan diskusi kelas untuk memperoleh pemahaman yang lebih mendalam dan tepat terhadap analisis karakter. Pada kesempatan ini, guru dapat mengambil peran untuk mengatur lalu lintas diskusi kelas agar persoalan-persoalan yang muncul dalam diskusi dapat dipecahkan dengan baik.

Bertolak dari simpulan diskusi yang dirumuskan oleh siswa, guru dapat menugasi siswa, misalnya menulis komentar siswa terhadap watak tokoh dalam cerpen yang telah dibacanya dalam bentuk esai singkat. Untuk tidak membebani guru dengan pekerjaan koreksi yang "menggunung" dalam memeriksa karya esai siswa, penilaian dapat dilakukan dengan dengan menyelenggarakan penilaian antar siswa. Untuk itu, guru dapat merumuskan rambu-rambu "penilaian" yang berisi komentar dan saran yang diberikan oleh siswa lain. Komentar dan saran ini diatahkan untuk perbaikan terhadap aspek isi, dan jika perlu aspek bahasa diabaikan.

"Pie chart" juga membantu siswa merefleksikan proses-proses pengkreasian
Sikap Pak Pong terhadap Jendral Paijo

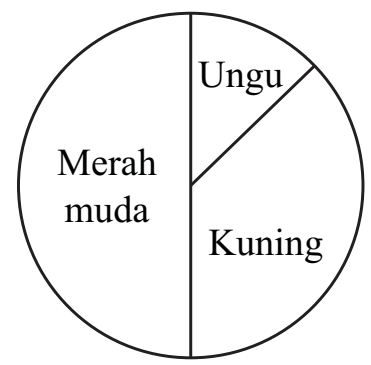

pengetahuan sosisal yang telah tertanam pada penggunaan ekspresi individual yang berbedabeda. Melalaui "pie chart" siswa dapat berbagi pengetahuan tentang simbol, pengetahuan sosial; dan berbagai pengetahuan tentang norma-norma sosial.

\section{Penggunaan Sketsa}

Data-data dari penelitian yang dilakukan oleh Within (1996) menunjukkan bahwa sketsa dan berbagi pendapat (sharing) terhadap representasi visual dapat mendorong siswa untuk mengakui potensi terbuka interpretasi sastra. Sketsa juga menyediakan kesempatan untuk berpikir kritis yang menyelesaikan demensi ekspresi melalui bahasa tulis dan lisan

Sketsa yang dihasilkan merupakan simbol temuan siswa untuk menyatakan makna, menggambar ide-ide dari konteks budaya mereka. Siswa-siswa juga menggunakan sistem komunikasi yang berbeda untuk membantu siswa lain membangun makna teks. Mengkreasikan dan dan mendiskusikan sketsa merupakan kegiatan yang berperan penting dari kerja sama untuk membangun makna..

Analisis respon siswa dalam bentuk sketsa juga menunjukkan bahwa penggunaan alat-alat dari sistem tanda non linguistik seperti matematika, dan seni dapat membantu siswa memperdalam pemahaman tema, konflik, dan hubungan antar tokoh. 
Guru berperan sebagai fasilitator dan bertanggungjawab untuk memperjelas ide-ide yang merupakan sikap siswa, menantang siswa untuk mengubah perspektif, dan membantu siswa berpikir lebih luas dan mendalam tentang elemen sastra, pengarang, dan isu-isu yang lebih luas sebagai implikasi dari sastra yang dibaca. Perhatikan contoh berikut. Perhatikan sketsa yang dibuat untuk menunjukkan hubungan perasaan tokoh Larasati dengan tokoh-tokoh lainnya dalam roman "BurungBurung Manyar" berikut ini.

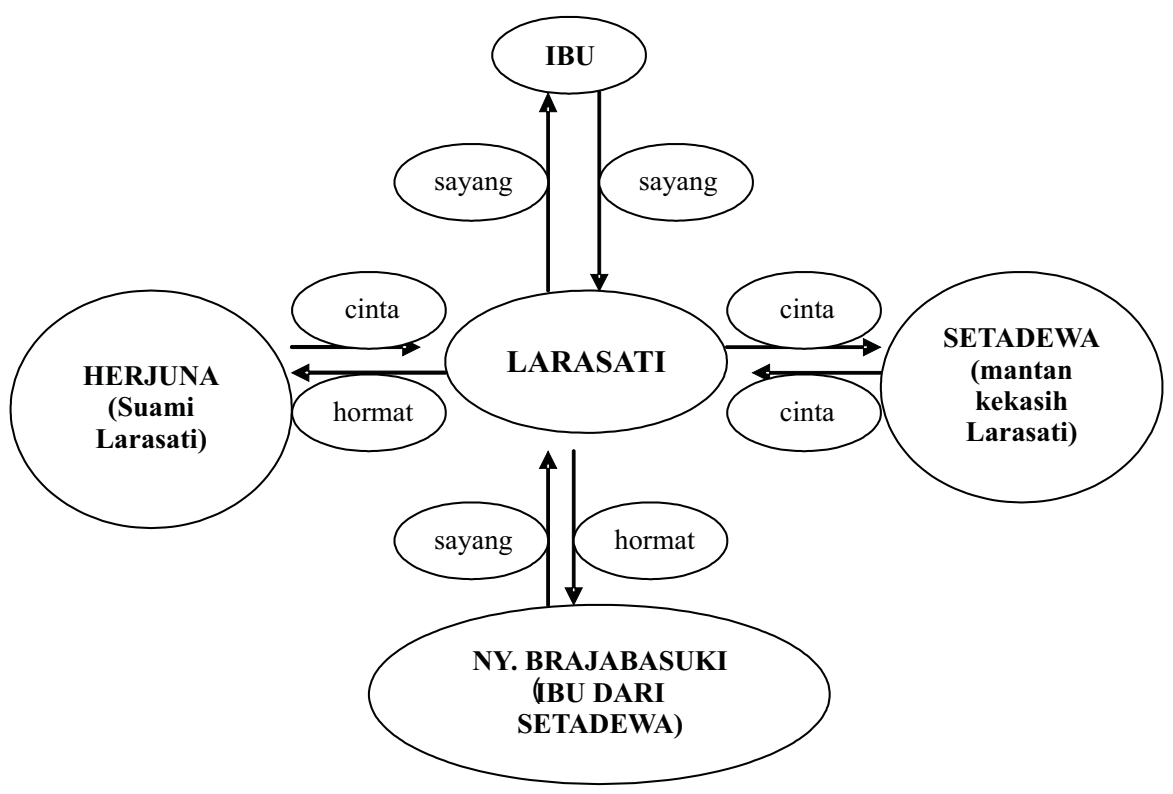

\section{Hubungan perasaan tokoh Larasati dengan tokoh lainnya dalam roman "Burung-Burung Manyar" Karya Y.B. Mangunwijaya}

Kegiatan analisis yang membutuhkan waktu dan konsentrasi yang lebih tinggi ini dapat dikerjakan secara berkelompok. Pembahasan dalam kelompok memberikan kesempatan kepada siswa untuk melakukan pembahasan terhadap fakta-fakta yang terhadapat dalam teks, menganalisis fakta tersebut dan mengorganisasikan menjadi konsep-konsep yang rasional. Konsep-konsep digunakan sebagai bahan diskusi kelas, sehingga hasil analisis dapat dipertajam dan diperoleh konsep yang lebih akurat. Tiap-tiap kelompok lebih lanjut dapat memanfaatkan hasil diskusinya sebagai bahan latihan penulisan kritik terhadap teks prosa yang dibacanya.

\section{Penggunaan Skala Penilaian}

Skala penilaian digunakan untuk merepresentasikan hasil penilaian siswa terhadap aspek tertentu dalam teks fiksi. Skala penilaian dibuat dengan menyusun matrik yang berisi seperangkat aspek yang terdapat dalam teks fiksi yang disusun secara kontras. Skala penilaian dapat membantu siswa-siswa yang mengalami kesulitan untuk menyatakan hasil apresiasinya secara verbal. Misalnya, untuk menyatakan karakter tokoh Datuk Maringgih dalam roman "Siti Nurbaya" dapat disusun matrik sebagi berikut. 


\begin{tabular}{|l|c|c|c|c|c|c|}
\hline Datuk Maringgih & Sangat & Agak & $\begin{array}{c}\text { Tidak ada, } \\
\text { keduanya, } \\
\text { tidak tahu }\end{array}$ & Agak & Sangat & \\
\hline Baik & & $\mathrm{X}$ & & & & Jelek \\
\hline Berani & $\mathrm{X}$ & & & & & Penakut \\
\hline Kikir & $\mathrm{X}$ & & & & & Pemurah \\
\hline Mata Keranjang & $\mathrm{X}$ & & & & & $\begin{array}{c}\text { Pengkhianat } \\
\text { bangsa }\end{array}$ \\
\hline Nasionalis & & $\mathrm{X}$ & & & & \\
\hline
\end{tabular}

Skala penialaian di atas secara sederhana menunjukkan rincian watak seorang tokoh dalam roman dengan teliti. Hal yang penting untuk dicatat ialah siswa harus dapat menjelaskan alasan penetapan watak tersebut dan menunjukkan bukti-bukti yang mendukung simpulannya baik secara lisan amaupun tertulis.

\section{Penggunaan Grafik}

Grafik digunakan untuk menggambarkan perkembangan aspek tertentu dalam teks prosa fiksi, misalnya perkembangan perasaan tokoh utama, karakter tokoh, dan plot cerita. Penyusunan grafik dilakukan dengan membuat matrik yang secara vertikal berisi aspek yang dilihat perkembangannya dan secara horisontal menunjukkan jumlah satuan unit peristiwa yang menggambarkan jumlah perubahan. Perhatikan contoh grafik yang dibuat dari perubahan-perubahan emosi tokoh sebuah cerpen anak-anak berikut.

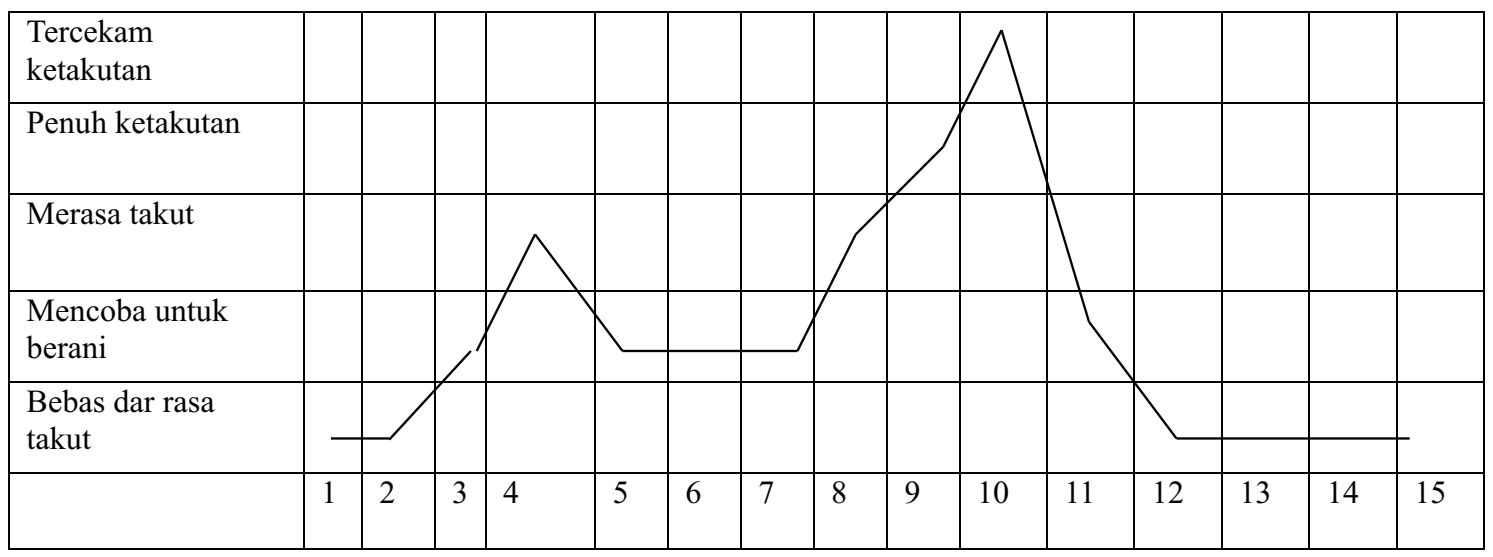

\section{Ringkasan peristiwa}

1. Ketika malam telah mulai larut, Tony mendengar suara dari ruang keluarga di lantai bawah.

2. Tony keluar kamar untuk mencari ibu.

3. Tony memberanikan diri turun ke lantai bawah untuk mencari ibu.

4. Tony ingin kembali ke kamar, tetapi merasa takut.

5. Tony memberanikan diri mengitari ruang keluarga.
6. Tony melihat Katy (kucing) yang tertidur di kursi, perasaannya sedikit lega.

7. Tony tidak melihat ibu, lalu bertanya kepada Katy, "Ibu di mana?"

8. Mengarahkan pandangan ke seluruh ruangan, tetapi tidak juga menemukan ibu, perasaan mulai takut.

9. Ketakutan Tony tak juga reda, lalu memegang ekor Katy. Katy kaget dan melompat dan seketika Tony merasa sangat takut. 
10. Tony menangis dan tercekam ketakutan.

11. Tony berusaha menguasai diri dan mengajak Katy membuka pintu untuk mencari ibu..

12. Melihat ibu di teras. belakang

13. Menemukan ibu sedang membaca sambil minum segelas susu dan makan kue..

14. Ibu menawarkan susu hangat dan kue.

15. Ibu percaya bahwa ia anak pemberani.
Representasi visual bentuk garfik juga bisa digunakan untuk menggabungkan hasil analisis dua atau lebih unsur sastra. Misalnya, analisis peristiwa yang dialami tokoh yang dihubungkan dengan perkembangan emosi dan logika tokoh, seperti yang dialami tokoh Ayah dalam cerpen "Dinding Anak" karya Danarto berikut.

\begin{tabular}{|c|c|c|c|c|c|}
\hline $\begin{array}{l}\text { Peristiwa yang } \\
\text { dialami tokoh } \\
\text { Emosi } \\
\text { dan togika } \\
\text { tokoh }\end{array}$ & $\begin{array}{l}\text { Ayah Dirawat } \\
\text { di rumah sakit } \\
\text { dan mendapat } \\
\text { bisikan dari } \\
\text { malaikat maut }\end{array}$ & $\begin{array}{l}\text { Ayah pulang } \\
\text { kembali ke } \\
\text { rumah }\end{array}$ & $\begin{array}{l}\text { Malam } \\
\text { tasyakuran atas } \\
\text { kesembuhan } \\
\text { ayah dan ayah } \\
\text { ditemui lagi } \\
\text { oleh malaikat } \\
\text { maut }\end{array}$ & $\begin{array}{l}\text { Ayah pergi ke } \\
\text { Pacitan untuk } \\
\text { memindahkan } \\
\text { Bibit (anak } \\
\text { bungsu yang } \\
\text { ditakdirkan } \\
\text { segera mati) }\end{array}$ & $\begin{array}{l}\text { Di dalam } \\
\text { pesawat } \\
\text { ayah ditemui } \\
\text { malaikat maut }\end{array}$ \\
\hline \multicolumn{6}{|l|}{ Gembira } \\
\hline \multicolumn{6}{|l|}{ Sedih } \\
\hline \multicolumn{6}{|l|}{ Berani } \\
\hline \multicolumn{6}{|l|}{ Takut } \\
\hline Logis & & & & & \\
\hline Emosional & & & & & \\
\hline
\end{tabular}

\section{Pengisian Matriks Berdasarkan Gradasi Perbedaan}

Pengisian matrik dimaksudkan untuk menampung simpulan-simpulan hasil analisis siswa terhadap teks prosa yang dibacanya. Matriks ini, misalnya digunakan oleh siswa untuk menetapkan gradasi perbedaan kualitas karakter antar tokoh dalam teks. Perhatikan contoh berikut matrik gradasi perbedaan kekuatan tokoh novel "Harimau! Harimau!" karya Muhtar Lubis berikut ini..

\begin{tabular}{|c|c|c|c|c|c|}
\hline & Sangat Kuat & Kuat & Tidak Kuat & Lemah & Sangat Lemah \\
\hline Sangat jelek & Wak Katok & & & & \\
\hline Jelek & & Wak Hitam & & & \\
\hline Tidak jelek/baik & & & Istri Wak Hitam & Sanip & \\
\hline Baik & & & & & Pendamar lain \\
\hline Sangat baik & Buyung & & & & \\
\hline
\end{tabular}




\section{Cerita Bergambar (Komik)}

Pemahaman terhadap kisah atau cerita dapat dikreasikan atau direpresentasikan dalam bentuk cerita bergambar atau penulisan komik. Kegiatan ini ilakukan dengan merancang cerita, dialog antar tokoh, monolog tokoh; mernacang setting, merancang sosok fisik dan gaya penampilan tokoh. Siswa sebaiknya diberi kebebasan untuk memilih sosok tokoh sesuai dengan imajinasi visual yang berlangsung dalam benaknya ketika membaca teks. Intervensi pihak lain seringkali justru akan membingungkan siswa.

\section{KESIMPULAN}

Strategi representasi visual dapat menjadi salah satu alternatif bagi guru dalam melaksnakan pembelajaran apresiasi prosa fiksi bagi siswa sekolah menengah. Strategi ini diharapkan dapat menhilangkan kejenuhan siswa dalam belajar sastra yang pada umumnya dikembangkan sebagai aktivitas verbal. Strategi representasi visual juga dapat membantu siswa yang mengalami kesulitan menyatakan hasil apresiasi sastra secara verbal. Hasil representasi visual merupakan medium diskusi untuk belajar berpikir secara sitematis, mengorganisasikan argumentasi dan mempertajam argumentasi, serta menghubungkan hasil interpretasi dengan pelajaran lain.

\section{DAFTAR PUSTAKA}

Departemen Pendidikan Nasional. 2003. Kurikulum Berbasis Kompetensi, Kompetensi Standar Mata Pelajaran Bahasa dan Sastra Indonesia. Mata Pelajaran Bahasa dan Sastra Indonesia SMP dan M.Ts.. Jakarta: Depdiknas.

Johnson, T.D., and Louis, D.R.. 1987. Literacy throught Literature. New Hampshire: Heineman.

Miall, D.S. 1996. Empawering the reader. Miall-Kuiken Reader Respon Research
Web Site. University of Alberta.

Perrine, L. 1983. Story and Structure. San Diego: Harcourt Brace Javanovich, Publishers.

Rodrigues, R.J. and Badaczewski. 1978. A Guide Book for Teaching Literature. Boston: Allyn and bacon, Inc.

Teew, A. 1987. Membaca dan Menilai Sastra. Jakarta: Gramedia.

Whitin. P.E. 1996. Exploring Visual Response to Literature. Research in the Teaching of English, Halaman 114-141. 